\title{
КОЭФФИЦИЕНТ КОМПЛЕКСНОСТИ КАК ИНСТРУМЕНТ ОЦЕНКИ УРОВНЯ ЗАГРЯЗНЕНИЯ И СПОСОБНОСТИ К САМООЧИЩЕНИЮ ВОДНОГО ОБЪЕКТА
}

\section{MULTIPURPOSE COEFFICIENT AS A TOOL FOR ESTIMATING A POLLUTION LEVEL AND ABILITY FOR SELF-PURIFICATION OF A WATER OBJECT}

\section{T. Evstifeeva M. Glukhovskaya}

Summary. The quality of surface water in almost all water bodies, with very few exceptions, in Russia does not meet the regulatory requirements. The Orenburg region is no exception. The Ural river, as the main watercourse and source of water supply for municipal and industrial consumers, already brings water with a fairly high level of pollution to the territory of the region, since many settlements and industrial enterprises of the Chelyabinsk region and the Republic of Bashkortostan discharge sewage into it and its main tributaries. Industrial and municipal effluents in Orenburg exacerbate the problem of pollution in the Urals. This article provides a spatial and temporal assessment of the quality and natural capabilities of the water of the Ural river within the city of Orenburg and the Orenburg city district to self-purification due to the action of physical and biological factors.

Keywords: water multipurpose coefficient; extremely high level of water pollution; control target, background target, water self- purification, hydrobionts. $\mathbf{y}$ рал - это главная река Оренбургской области, пересекающая с востока на запад территорию 10 административных районов и имеющая общую протяженность в субъекте 1164 км. Почти 2/3 территории области относится к её бассейну.

Если учесть, что до границ Оренбургской области Урал пересекает территорию еще 2-х крупнейших субъектов РФ и общая площадь водосбора составляет 231 тыс. км, вполне объясним тот факт, что на территорию области вода Урала приходит уже с достаточно высоким уровнем загрязнения [1]. Подвергаясь дополнительному загрязнению на территории области, вода, практически теряет способность к самоочищению, т.к. высокий уровень загрязнения приводит к торможению естественных окислительных процессов, способствует гибели микроорганизмов и других гидробионтов, уча-

\author{
Евстифеева Татьяна Александровна \\ К.с.-х. н., доцент, Оренбургский государственный \\ университет \\ ta_evst@mail.ru \\ Глуховская Марина Юрьевна \\ К.т. н., доцент, Оренбургский государственный \\ университет
}

Аннотация. Качество поверхностных вод практически всех водных объектов, за очень редким исключением, территории России не отвечает нормативным требованиям. Оренбургская область не является исключением. Река Урал как основной водоток и источник водоснабжения коммунальных и промышленных потребителей, на территорию области уже приносит воды с достаточно высоким уровнем загрязнения, т.к. выше по течению реки в нее и основные притоки осуществляется сброс сточных вод многих населенных пунктов и промышленных предприятий Челябинской области и Республики Башкортостан. Промышленные и коммунальные стоки Оренбурга усугубляют проблему загрязнения Урала. В данной статье проведена пространственно -временная оценка качества и природных возможностей воды реки Урал в пределах г. Оренбург и Оренбургского городского округа к самоочищению за счет действия физических и биологических факторов.

Ключевые слова: коэффициент комплексности загрязненности воды; высокий и экстремально высокий уровень загрязнения; контрольный створ, фоновый створ, самоочищение воды, гидробионты.

ствующих в природных процессах очистки, увеличивая скорость деградации водного объекта.

Это обуславливает необходимость существования системы непрерывного комплексного анализа состояния данного водотока. Такой анализ включает учет и контроль качественных и количественных характеристик во времени, наблюдений за гидрологическими, гидрохимическими гидробиологическими показателями состояния воды, с дальнейшим сбором, передачей и обработкой этих данных, что преследует цель своевременного выявления, прогнозирования и, в случае необходимости, предотвращения вероятных отрицательных процессов, снижающих качество воды.

При проведении мониторинга чрезвычайно важен выбор параметров контроля. Одним из самых инфор- 
Таблица 1. Пограничные значения кратности превышения ПДК для веществ различных классов опасности

\begin{tabular}{|c|c|c|}
\hline \multirow[b]{2}{*}{ Ингредиенты и показатели качества воды } & \multicolumn{2}{|c|}{ Кратность превышения ПДК для случаев } \\
\hline & высокого уровня загрязненности & $\begin{array}{l}\text { экстремально высокого уров- } \\
\text { ня загрязненности }\end{array}$ \\
\hline 1-го - 2-го классов опасности & {$[3-5]$} & $\geq 5$ \\
\hline $\begin{array}{l}\text { 3-го - 4-го классов опасности, кроме нефтепродуктов, } \\
\text { фенолов, меди, железа общего }\end{array}$ & {$[10-50]$} & $\geq 50$ \\
\hline $\begin{array}{l}\text { 4-го класса опасности - нефтепродукты, фенолы, медь, } \\
\text { железо общее }\end{array}$ & {$[30-50]$} & $\geq 50$ \\
\hline
\end{tabular}

мативных показателей, позволяющих оценить качество воды во времени и пространстве, является коэффициент комплексности загрязненности воды, который позволяет оценивать уровень загрязненности воды в пробе, створе, пункте, водотоке и т.д. Данный коэффициент используется для интерпретации результатов расчета в оценочные параметры поверхностного водного объекта. Это простая, и. в то же время, достаточно достоверная характеристика уровня негативного техногенного воздействия на поверхностные водоемы. Расчет значения коэффициента комплексности загрязненности воды $K$ проводится для каждого результата анализа по формуле:

$$
K_{f j}=\frac{N_{f j}}{N_{f j}} \times 100 \%,
$$

где $K_{f j}$ - коэффициент комплексности загрязненности воды в $f$-м результате анализа для $j$-го створа;

$\hat{N}_{f j}$ - количество нормируемых ингредиентов и показателей качества воды, содержание или значение которых превышает соответствующие им ПДК в $f$-м результате анализа для $j$-го створа;

$N_{f j}$ - общее количество нормируемых ингредиентов и показателей качества воды, определенных в $f$-м результате анализа для $j$-го створа [2].

Интервал времени, который подлежит оценке, в данной методике охарактеризован посредством среднего значения коэффициента комплексности $K_{j}$ :

$$
K_{j}=\frac{\sum_{f=1}^{m i} K_{f j}}{n_{k j}},
$$

где $n_{k j}$ - общее количество результатов анализа воды, для которых рассчитаны значения коэффициента комплексности в $j$-м створе за $k$-й период времени [2].

С целью выявления частоты встречаемости высокого и экстремально высокого уровней загрязнения проводят расчеты учитывающие количество веществ, фактическая концентрация которых превышает ПДК в соответствии границами, обозначенными в таблице 1.
При высоком уровне загрязнения воды, коэффициент комплексности рассчитывается следующим образом:

$$
K_{\mathrm{z} 3 f j}=\frac{K_{\mathrm{B} 3 f j}}{N_{f j}} \times 100 \% \text {, }
$$

где $K_{\text {взf }}$ - коэффициент комплексности высокого уровня загрязнения воды для $f$-го результата химического анализа в $j$-м створе;

$\dot{N}_{\text {взлj }}$ - количество нормируемых ингредиентов и показателей качества воды, содержание или значение которых превышает соответствующие им критерии высокого загрязнения [2].

Аналогично рассчитываются коэффициенты для экстремально высокого уровня загрязнения, но в числитель в этом случае выносится число ингредиентов, концентрация которых превышена в количество раз, обозначенных для данной категории [3].

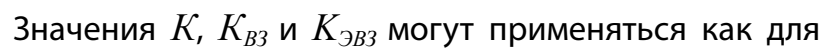
оценки современного состояния водоема, так и с целью определения тенденций изменения качества воды за определенный промежуток времени или для сравнительного анализа уровня загрязнения воды в различных водных объектах.

Низкое значение коэффициента ( $<<10 \%)$, свидетельствует о том, что загрязнение сформировано единичными веществами. Высокое значение $K(\geq 10 \%)$, свидетельствует о низком качестве воды и повышенном влиянии на водный объект антропогенных факторов.

В процессе исследований в качестве пунктов отбора проб для проведения химического анализа воды выбраны три последовательно расположенных створа (фоновый и два контрольных), в соответствии с требованиями для водотоков, характеризующихся интенсивным водообменом и значительным стоком загрязнителей, расположенных на территории г. Оренбург и Оренбургского городского округа: 
Таблица 2. Динамика значений коэффициента комплексности загрязненности воды (К),\%

\begin{tabular}{|c|c|c|c|c|c|c|c|c|c|c|c|c|c|}
\hline \multirow{2}{*}{ Створы } & \multicolumn{12}{|l|}{ Годы } & \multirow{2}{*}{$\begin{array}{l}\mathbf{K}_{c p} \\
2007- \\
2018\end{array}$} \\
\hline & 2007 & 2008 & 2009 & 2010 & 2011 & 2012 & 2013 & 2014 & 2015 & 2016 & 2017 & 2018 & \\
\hline$C \Phi$ & 28,3 & 30,1 & 28,7 & 33,8 & 32,5 & 35,7 & 34,1 & 32,5 & 35,7 & 29,2 & 26,2 & 31,8 & 31,6 \\
\hline CK1 & 51,4 & 46,7 & 42,2 & 47,9 & 41,3 & 44,1 & 45,7 & 44,5 & 45,7 & 34,6 & 40,3 & 46,7 & 44,3 \\
\hline CK2 & 33,3 & 35,2 & 30,2 & 38,4 & 34,1 & 37,2 & 35,2 & 32,7 & 37,2 & 30,2 & 35,1 & 34,3 & 34,4 \\
\hline
\end{tabular}

Примечание: СФ - фоновый створ; СК1 - Контрольный створ (0.5 км ниже ГОС); СК2 - Контрольный створ (5,0 км ниже ГОС)

Таблица 3. Результаты ранжирования значений коэффициентов комплексности загрязненности воды за период исследования

\begin{tabular}{|c|c|c|c|c|c|c|c|c|}
\hline \multicolumn{3}{|c|}{ Фоновый створ } & \multicolumn{3}{|c|}{\begin{tabular}{|l|} 
Контрольный створ \\
(0.5 км ниже ГОС)
\end{tabular}} & \multicolumn{3}{|c|}{\begin{tabular}{|l|} 
Контрольный створ \\
(5,0 км ниже ГОС)
\end{tabular}} \\
\hline K & годы & ранг & K & годы & ранг & K & годы & ранг \\
\hline 35,7 & 2012 & 1 & 51,4 & 2007 & 1 & 38,4 & 2010 & 1 \\
\hline 35,7 & 2015 & 1 & 47,9 & 2010 & 2 & 37,2 & 2012 & 2 \\
\hline 34,1 & 2013 & 2 & 46,7 & 2018 & 3 & 37,2 & 2015 & 2 \\
\hline 33,8 & 2010 & 3 & 46,7 & 2008 & 3 & 35,2 & 2008 & 3 \\
\hline 32,5 & 2011 & 4 & 45,7 & 2013 & 4 & 35,2 & 2013 & 3 \\
\hline 32,5 & 2014 & 4 & 45,7 & 2015 & 4 & 35,1 & 2017 & 4 \\
\hline 31,8 & 2018 & 5 & 44,5 & 2014 & 5 & 34,3 & 2018 & 5 \\
\hline 30,1 & 2008 & 6 & 44,1 & 2012 & 6 & 34,1 & 2011 & 6 \\
\hline 29,2 & 2016 & 7 & 42,2 & 2009 & 7 & 33,3 & 2007 & 7 \\
\hline 28,3 & 2007 & 8 & 41,3 & 2011 & 8 & 32,7 & 2014 & 8 \\
\hline 28,7 & 2009 & 9 & 40,3 & 2017 & 9 & 30,2 & 2009 & 9 \\
\hline 26,2 & 2017 & 10 & 34,6 & 2016 & 10 & 30,2 & 2016 & 9 \\
\hline
\end{tabular}

фоновый - в черте города;

- 1-й контрольный (СК 1) - на расстоянии 500 м ниже сброса сточных вод городскими очистными сооружениями (ГОС);

- 2-й контрольный (СК 2) - на расстоянии 5000 м ниже ГОС [4].

При расчете коэффициента (К) соблюдались условия учета приблизительно равного количества анализируемых ингредиентов. Допустимая разница составляла не более $30 \%$.

Полученные данные за 11 лет исследования по трем створам сведены в таблицу 2.

Представленные в таблице результаты расчетов позволяют определить такие экстремальные величины вариационных рядов, как $\mathrm{K}_{\min }$ и $\mathrm{K}_{\max }$. Для фонового створа они равны 26,2\% и 35,7\%, для контрольного створа (CK 1) - 34,6\% и 51,4\%, для контрольного (CK 2) - 30,2\% и 38,4\%. Средние значения коэффициентов комплексности загрязненности воды, соответственно, равны: 31,6; 44,$3 ; 34,4$.
Низкий размах полученных значений $(9,5,16,8$ и 8,2) для вышеуказанных створов, свидетельствует о стабильности, проявляющейся в постоянном, достаточно высоком уровне загрязнения.

Во всех створах за весь период исследования величина коэффициента комплексности загрязненности воды не опускалась ниже $26 \%$, что более чем в 2,5 раза превышает значение верхней границы показателя, свидетельствующего о загрязнении воды единичными веществами. Таким образом, полученные значения подтверждают, что превышение ПДК наблюдается по значительному перечню ингредиентов.

В течение всего исследуемого периода, наибольшее количество веществ, фактическая концентрация которых превышает нормативные значения, характерно для проб, отобранных в контрольном створе, расположенном в 0.5 км ниже очистных сооружений, наименьшее в фоновом створе.

Для более полной характеристики найденной совокупности значений было проведено ранжирование, ко- 
Таблица 4. Значения кратности превышения ПДК приоритетных загрязняющих веществ

\begin{tabular}{|c|c|c|c|c|c|c|c|c|c|c|c|c|}
\hline \multirow{3}{*}{$\begin{array}{l}\text { Наимено-вание } \\
\text { загрязня-юще- } \\
\text { го вещества }\end{array}$} & \multicolumn{4}{|c|}{ Фоновый створ } & \multicolumn{4}{|c|}{$\begin{array}{l}\text { Контрольный створ } \\
\text { (0.5 км ниже ГОС) }\end{array}$} & \multicolumn{4}{|c|}{\begin{tabular}{|l|} 
Контрольный створ \\
(5,0 км ниже ГОС)
\end{tabular}} \\
\hline & \multicolumn{12}{|l|}{ годы } \\
\hline & 2015 & 2016 & 2017 & 2018 & 2015 & 2016 & 2017 & 2018 & 2015 & 2016 & 2017 & 2018 \\
\hline медь & 2,3 & 2,6 & 1,9 & 2,2 & 2,5 & 2,8 & 2,7 & 3,1 & 1,9 & 2,1 & 2,0 & 2,6 \\
\hline ХПК & 1,9 & 2,0 & 1,9 & 1,9 & 1,8 & 1,9 & 2,0 & 2,1 & 1,8 & 1,8 & 1,8 & 1,9 \\
\hline БПК & 1,0 & 1,1 & 1,1 & 1,1 & 1,1 & 1,2 & 1,2 & 1,2 & 1,1 & 1,1 & 1,1 & 1,1 \\
\hline азот нитритный & 1,2 & 1,4 & 0,7 & 1,1 & 1,4 & 2,9 & 2,2 & 2,6 & 1,6 & 2,5 & 2,0 & 1,9 \\
\hline
\end{tabular}

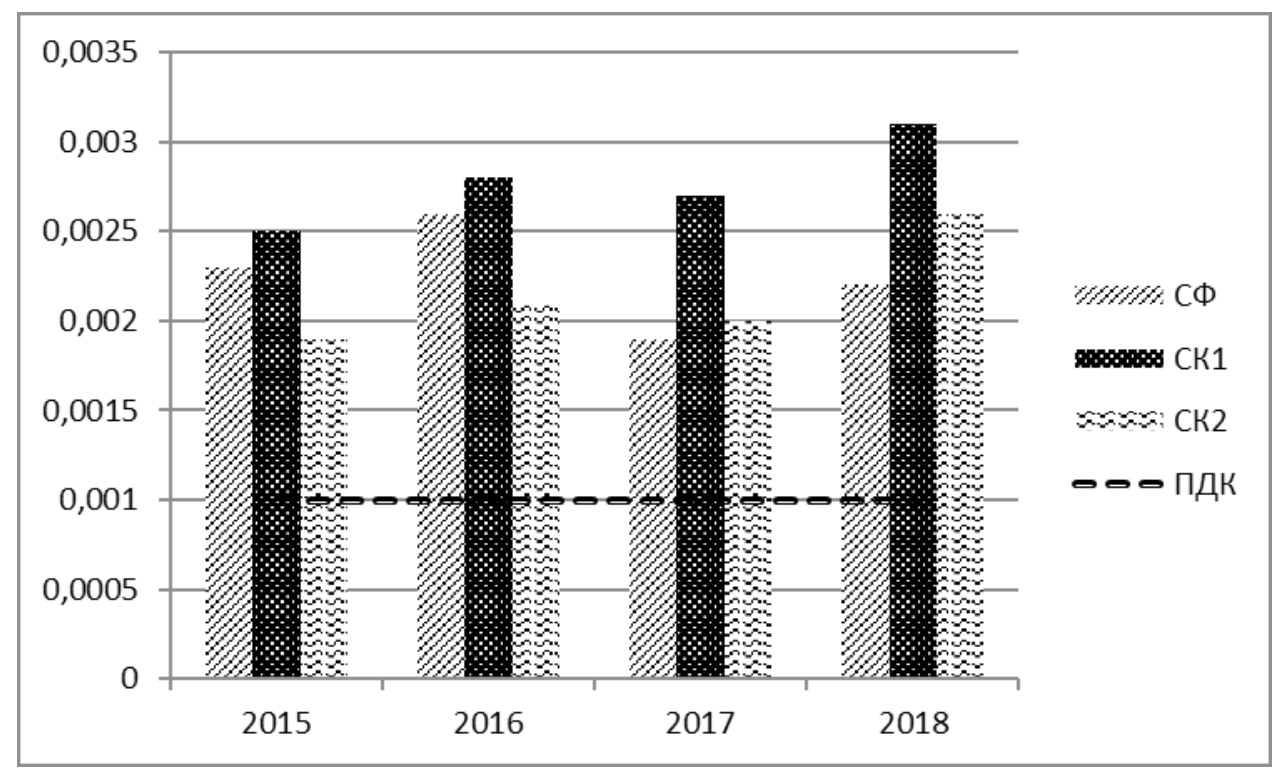

Рис. 1. Концентрация меди в воде исследуемых створов

торое позволило выявить периоды максимально высокого антропогенного воздействия (таблица 3).

Результаты исследований показали, что максимальное значение определяемого показателя наблюдалось в фоновом створе в 2012 и 2015 годах, в контрольном (0,5 км ниже ГОС) - в 2007 году, в контрольном (5,0 км ниже ГОС) - в 2010, а минимальное - в 2017; 2016; 2016, соответственно.

Проведенные исследования показали, что качество воды в контрольном створе 0,5 км ниже ГОС не зависит от уровня ее загрязнения в фоновом. Так например, наиболее загрязненная вода в первом контрольном створе наблюдалась в 2007 году, тогда как в фоновом створе, напротив, уровень загрязнения был близок к минимальному. В 2007 году в первом створе уровень загрязнения был на 45\% больше чем в фоновом, а максимальное загрязнение в фоновом створе наблюдалось в 2012 и 2015 годах, что лишь на 23,5\% и 28,01\% меньше чем в створе расположенном на 0,5 км ниже ГОС.
Таким образом, уровень загрязнения участка водотока, подверженного влиянию урбанизированных территорий, практически полностью, определяется объёмом поступления на ГОС сточных вод и качеством воды сбрасываемой в водный объект после очистки.

Поиск методов решения проблемы зависит, в первую очередь, от качественно и количественного состава загрязняющих веществ, поступающих в реку.

Основными загрязняющими веществами, характерными для водоемов Оренбургской области, являются соединения тяжелых металлов, азот аммонийный, нитритный и нитратный, сульфаты, магний, нефтепродукты, легкоокисляемые органические вещества по БПк5 (биохимическому потреблению кислорода) и органические вещества по ХПК (химическому потреблению кислорода).

По результатам анализов были выявлены приоритетные загрязняющие вещества, концентрация которых 
Таблица 5. Соотношение концентраций загрязняющих веществ, в процентах

\begin{tabular}{|c|c|c|c|c|c|c|c|c|c|}
\hline \multirow{3}{*}{$\begin{array}{l}\text { Наименование } \\
\text { загрязняющего } \\
\text { вещества }\end{array}$} & $\begin{array}{l}\text { Фоновый } \\
\text { створ }\end{array}$ & \multicolumn{4}{|c|}{$\begin{array}{l}\text { Контрольный створ } \\
\text { (0.5 км ниже ГОС) }\end{array}$} & \multicolumn{4}{|c|}{$\begin{array}{l}\text { Контрольный створ } \\
\text { (5,0 км ниже ГОС) }\end{array}$} \\
\hline & \multicolumn{9}{|l|}{ период } \\
\hline & 2015-2018 & 2015 & 2016 & 2017 & 2018 & 2015 & 2016 & 2017 & 2018 \\
\hline медь & 100 & 108,7 & 107,7 & 142,1 & 140,9 & 82,6 & 80,8 & 105,3 & 118,2 \\
\hline азот нитритный & 100 & 116,7 & 207,1 & 314,3 & 236,4 & 133,3 & 178,6 & 285,7 & 172,7 \\
\hline
\end{tabular}

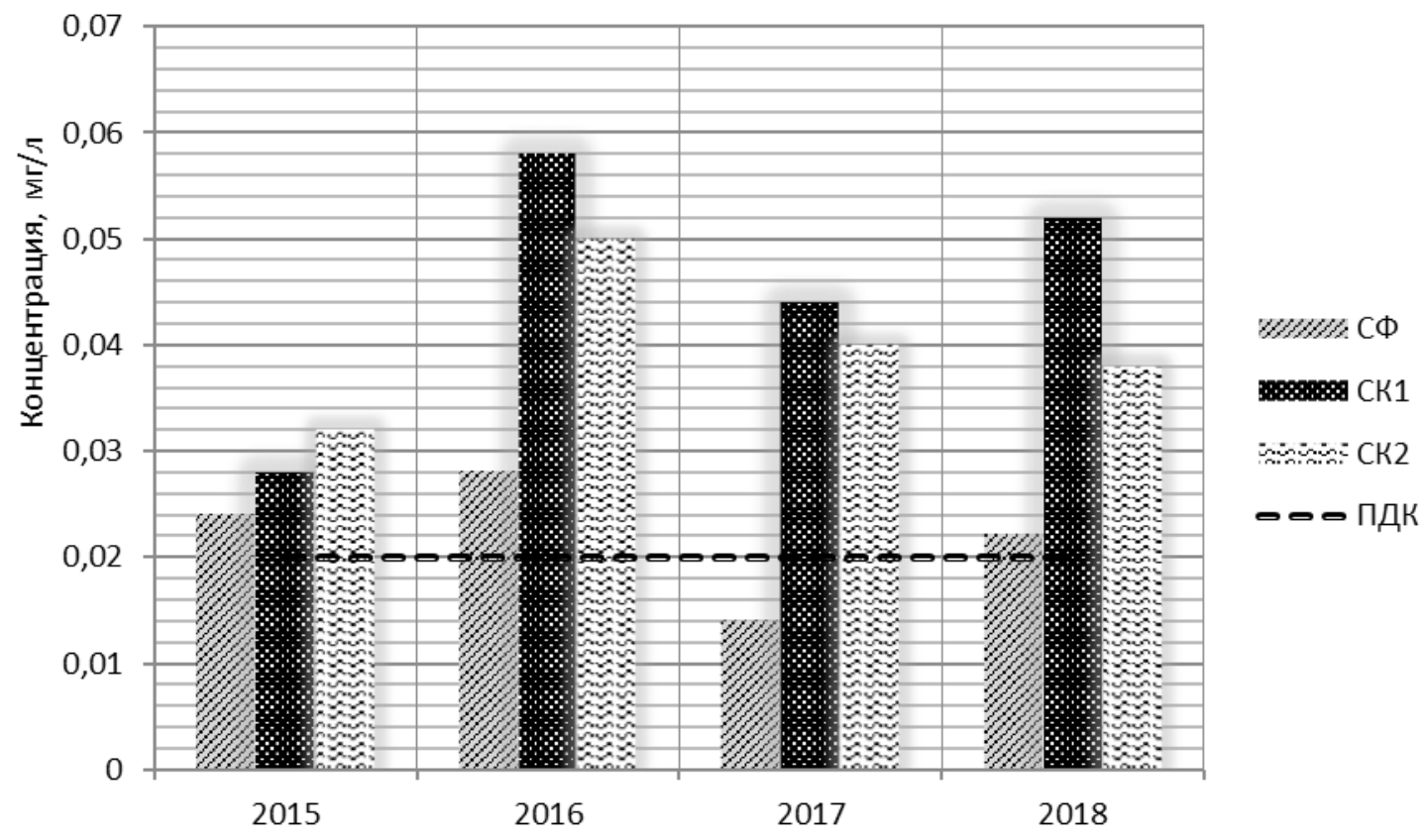

Рис. 2. Концентрация азота нитритного в воде исследуемых створов

во всех створах и за весь период исследований превышала значения нормативных показателей [5]. К ним относятся медь, азот нитритный, биохимическое и химическое потребление кислорода. В таблице 4 приведены значения кратности превышения ПДК наиболее значимых загрязняющих веществ за последние годы.

В ходе анализа полученных данных было определено, что только по двум веществам из 4 приоритетных уровень загрязнения даже через пять километров не снижается до фонового значения, что связано с высокой концентрацией этих веществ в пробах створа, ближайшего к ГОС.

Фактические концентрации меди и азота нитритного в воде исследуемых створов представлены на рисунках 1,2 .

Анализ данных свидетельствует о том, что (по меди) до 2017 г., а по азоту нитритному — до 2016 г., река еще обладала способностью к восстановлению своих первоначальных свойств за счет разбавления и самоочищения, но, в последние годы, снижение концентрации 3В до прежнего уровня не происходит. Концентрации, как меди, так и азота нитритного в фоновом створе снизилась, а в створе, расположенном на расстоянии 0,5 км от ГОС - повысились, что позволяет сделать вывод о снижении уровня антропогенного загрязнения на водоток выше по течению реки и об увеличении в результате влияния промышленных и бытовых стоков с территории г. Оренбург.

С целью выявления количественной оценки вклада города Оренбург в уровень загрязнения воды р. Урал, было определено соотношение концентраций 2-х приоритетных ЗВ в пробах изучаемых створов, при этом уровень 3В в фоновом створе был принят за 100\% (табл. 5).

Определено, что в створе, ближайшем к ГОС г. Оренбург, концентрации ЗВ по отношению к фону могут повы- 
шаться на 236,4\%, а на расстоянии 5 км от ГОС, несмотря на природные механизмы очищения и высокий уровень разбавления, до 285,7\%, по сравнению с фоном.

Таким образом, несмотря на имеющуюся способность к самоочищению вотодотока, о чем свидетельствует стабильное снижение коэффициента в створе, находящемся в 5 км ниже по течению от основного источника загрязнения, концентрации 3В и объемы сбросов ГОС г. Оренбурга намного превосходят природные возможности к восстановлению качества воды. Водные объекты способны самостоятельно, благодаря процессам многократного разбавления и биологическим механизмам, нейтрализовать часть загрязнений. Но, самоочищение поверхностных вод с помощью живых организмов в природе протекает медленно, а высокий уровень их загрязнения, как тяжелыми металлами, так и биогенными веществами, значительно тормозит скорость естественных механизмов, что приводит, в нашем случае, к сведению к минимуму природных возможностей водоемов к самовосстановлению.

Сложившаяся ситуация требует пристального внимания и разработки научно-обоснованного комплекса мероприятий для предотвращения поступления столь высоких концентраций загрязняющих веществ в воду реки Урал в пределах урбанизированных территорий. Одной из ключевых задач является доведение объема сбросов загрязнителей до уровня, не превышающего потенциала самоочищения конкретного водного объекта.

Полученные результаты свидетельствуют о том, что первоочередной становится задача как снижения поступления в составе сточных вод урбанизированных территорий таких загрязнителей как медь, азот нитритный и органические вещества, так и применения современных методов очистки от них на городских очистных сооружениях.

В целом, следует отметить, что настолько же критично складывается ситуация со всеми водными объектами области, поэтому необходимо направить усилия не только на глубокие исследования в форме комплексного мониторинга качества поверхностных вод, но и решать усугубляющиеся проблемы путем внедрения технологий, обеспечивающих ликвидацию, либо значительное снижение объема поступления в водотоки неочищенных или недостаточно очищенных стоков, обеспечения контроля за соблюдением особого режима охраны на территории водоохранных зон и, безусловно, многократного ужесточения ответственности за нарушение требований водного законодательства. Эти меры, несмотря на значительные финансовые и трудовые затраты, позволят, в будущем, эффективно решать проблемы деградации водных объектов Российской Федерации.

\section{ЛИТЕРАТУРА}

1. Морозова, 3. Ш. Экологическая характеристика Оренбургской области [Электронный ресурс] / Морозова 3. Ш., Глуховская М. Ю. // Университетский комплекс как региональный центр образования, науки и культуры: материалы Всерос. науч.-метод. конф.— Оренбург,2014. — С. 963-967

2. Руководящий документ РД 52.24.643-2002 «Методические указания. Метод комплексной оценки степени загрязненности поверхностных вод по гидрохимическим показателям» (утв. и введен в действие Федеральной службой России по гидрометеорологии и мониторингу окружающей среды 01.01 .2004 г.) [Электронный ресурс].— Режим доступа: https://base.garant.ru/70467388/

3. Евстифеева, Т. А. Оценка динамики качества воды поверхностных водных источников города Оренбурга (на примере р. Урал) $3 а$ период с 2007 по 2017 годы [Электронный ресурс] / Т. А. Евстифеева, М. Ю. Глуховская, Ж. А. Аликина // Региональные проблемы геологии, географии, техносферной и экологической безопасности: сб. ст. Всерос. науч.-практ. конф., 18-20 нояб. 2019 г., Оренбург / Минобрнауки России [и др.].— Электрон. дан.— Оренбург: Полиарт,2019.- - С. 228-231

4. Министерство природных ресурсов, экологии и имущественных отношений Оренбургской области [Электронный ресурс]: Государственный доклад « 0 состоянии и $0 б$ охране окружающей среды Оренбургской области в 2007-2018 годах»._— Режим доступа: https://mpr.orb.ru/ecology/129/?special_version=Y

5. Приказ Минсельхоза России от 13 декабря 2016 года № 552 «06 утверждении нормативов качества воды водных объектов рыбохозяйственного значения, в том числе нормативов предельно допустимых концентраций вредных веществ в водах водных объектов рыбохозяйственного значения (с изменениями на 12 октября 2018 года) [Электронный ресурс].— Режим доступа: http://docs.cntd.ru/document/420389120 